Schools Collaborating with Experts in the Community

\title{
Creating a belonging place
}

\section{OWAIRAKA DISTRICT SCHOOL}

Sue McDowall and Jenny Whatman 
New Zealand Council for Educational Research P O Box 3237

Wellington

New Zealand

www.nzcer.org.nz

ISBN 978-0-947509-36-1

(c) NZCER 2016 


\section{Acknowledgements}

NZCER would like to thank the Owairaka District School staff, students, and community volunteers who gave generously of their time and expertise as we undertook this case study. 


\section{Contents}

Acknowledgements III

1. Introduction 1

2. Research design 2

3. Owairaka District School 3

Programmes 3

Community experts at Owairaka School 4

Community experts and Garden to Table 4

4. How did it work? 5

Structures and processes 5

Enlisting volunteers and making volunteers feel welcome 5

Promoting community experts' ownership and agency 6

\section{Curriculum 7}

A curriculum that enables involvement of community experts 7

A curriculum centred on people and place 7

Impact of community experts on curriculum 8

6. Effect on teachers and teaching $\mathbf{1 0}$

Opportunities to be a learner and to connect with the community 11

7. Effect on students and their learning 12

A sense of belonging 12

Purpose, agency, authenticity 13

Opportunities to work with diverse others 13

Opportunities to learn from adults other than teachers 14

Knowledge and skills 14

Opportunities for all students to experience success 15

8. What was the impact for community experts? 17

A sense of belonging 17

Opportunities to learn new skills 18

Understanding and influencing the curriculum 18

9. What was the effect on the wider community? 19

10. Challenges and considerations 20

Fundraising 20

Community experts are not teachers 21

Accountability 21

11. Sustainability 22

12. Discussion 23

\section{References 24}




\section{1. Introduction}

This report presents findings from a case study carried out by NZCER about Owairaka District School and their collaboration with community members as part of implementing Garden to Table and other related initiatives. It is the second case study carried out as part of a wider investigation into successful and sustained collaborations between New Zealand schools and community and professional experts ${ }^{1}$ that support relevant, connected, future-oriented learning ${ }^{2}$ for students. The first case study All the School's a Stage (McDowall \& Whatman, 2016) described a collaboration between performing and visual artists and staff at Pakuranga Intermediate School.

The core argument for the type of school-community relationships we are focusing on is the benefit for students' learning. However, the primary focus for this research is to understand the impacts and experiences of adults who work together in these collaborations; that is, the teaching professionals and the community experts. The reason for this focus is that adults (as teachers, school leaders, policy decision makers, parents, or voters) shape the educational system. For system-wide shifts to occur, it is important to know how and why adults think it is beneficial for school learners to have access to community expertise as part of their school learning, and how they think this can happen effectively.

1 By "community and professional experts", we mean people who are not necessarily educators or teachers, but who have knowledge and expertise in their own professional areas (or because of their role in the community) and are working with schools in ways that support learners to connect with that knowledge and expertise.

2 By "future-oriented learning", we mean approaches and practices that align with contemporary perspectives about the kinds of learning and learning opportunities young people need in order to have a good life in a well-functioning society for the 21st century. (This kind of learning overlaps with, but also goes beyond, current frames of learning success such as achievement and progression into tertiary education and employment.) 


\section{2. \\ Research design}

Four questions framed our research:

1. How do teachers and community experts build and sustain reciprocal knowledge-building relationships that transform learning and teaching from "business as usual" schooling approaches?

2. What are the enabling conditions (and barriers) for teachers and community experts to work together to support future-oriented learning?

3. How do adults' views about learning, teaching, curriculum, schooling, and their own professional practice change as a result of these collaborations?

4. What are the impacts for learners, educators (teachers and school leaders), the community experts, and possibly others, such as whānau/family/wider community?

We chose a case study approach as being most appropriate to address the "what", "how", and "why" of a situation (Yin, 2003). The advantage of a case study approach is that it can provide the "force of example" (Flyvbjerg, 2006, p. 228) as a source of understandings. As noted by Flyvbjerg, the advantage of the case study is that "it can 'close in' on real-life situations and test views directly in relation to phenomena as they unfold in practice" (Flyvbjerg, 2006 p. 235).

We selected Owairaka District School as a case study because, like Pakuranga Intermediate School, Owairaka has evidence of: sustained relationships between teachers and community experts; shifts in "business as usual" teaching and learning practices; and benefits for learners, teachers, and community experts.

One of the researchers had been introduced to Garden to Table in another research project and attended an open day at Owairaka School to find out more about the scheme. We then visited the school towards the end of 2015 and observed a typical day at the school with community experts coming and going as part of the Garden to Table programme and other activities. We interviewed the principal and a sample of teachers, including the two associate principals, and community volunteers. We spoke with two groups of students who had been or were currently involved in Garden to Table. We then identified key themes from the observation and interview notes and used these to structure the findings presented in this report. 


\section{3. \\ Owairaka District School}

Owairaka District School ${ }^{3}$ is situated in Mt Albert, Auckland. It is a Decile 3 school with more than 500 Year 1-6 students. The school includes more than 50 different ethnic groups, with larger groups being New Zealand Māori, New Zealand European/Pākehā, Tongan, Indian, and South East Asian. The school has a high proportion of specialist teachers to support the wide range of learning needs present in the diverse student population, including bilingual teachers, and a strong teacher aide team.

The mission statement of Owairaka District School is, "I can do it, you can do it, and together we can achieve our goals". The school tag line is "Growing great learners", and the goals of the school are for students to have a love of learning, excel in literacy and numeracy, be environmentally active, and be socially well prepared.

The values, goals, and mission statement are reflected in the physical school environment. In a walk around the grounds you can enjoy many sights not always found in schools: raised gardens of flowers and vegetables; a henhouse; bee hives; a pizza oven; a Samoan fale; outdoor sculptures; a potting shed; and an orchard. At the school entrance is a signpost made by students identifying many of the students' countries of origin.

\section{Programmes}

The school makes use of a range of programmes that support its values, vision, and goals, and that the school sees as interconnected. These include Enviroschools, Garden to Table, Wastewise, Health Promoting Schools, and You Can Do It.

The Enviroschools programme $\mathrm{e}^{4}$ is organised on eight theme areas of waste, food production, food distribution, biodiversity, water, energy, energy building, and is aligned to the New Zealand curriculum (Ministry of Education, 2007). The aim of the organisation is to "to foster a generation of people who instinctively think and act sustainably." Sustainability includes people working together with positive

3 http://www.owairaka.school.nz/

4 Enviroschools (http://www.enviroschools.org.nz/about-enviroschools) began in 1993 with three pilot schools in the Waikato. The Enviroschools Foundation was established in 2002 and today there are almost 1,000 schools and ECE centres involved in 16 regions (250,000 children with 100,000 actively involved). Enviroschools is funded by the Ministry for the Environment and supported by the national body-the Toimata Foundation-16 regional co-ordinators, and local trained facilitators who guide, advise and motivate schools. 
energy, regeneration of connected communities that care for each other and for the environment, and valuing Māori knowledge.

The Garden to Table Trust was established in 2009 to develop and introduce a curriculum-linked food education programme. The Garden to Table programme, originally inspired by the Stephanie Alexander Kitchen Garden Program, was established in Melbourne, Australia in 2001. It was adopted in New Zealand with the aim of introducing primary and intermediate school students to growing, harvesting, cooking, and sharing fresh, seasonal produce in their own school, with the help of volunteers and teachers. Garden to Table schools identify a teacher as "programme champion" to oversee Garden to Table, recruit, induct, and support kitchen and garden specialists and volunteers from the community, and encourage classroom teachers to use the Garden to Table classes to support the curriculum. The programme champion liaises with the Garden to Table area co-ordinator when advice or support is needed. Owairaka School joined Garden to Table in 2011, and was one of the first New Zealand schools to do so. ${ }^{5}$

The Wastewise programme involves using resources carefully, and reducing waste going to landfills and the money spent on waste disposal by recycling paper and plastic, and by using either a worm farm or bokashi bin to dispose of food scraps.

The Health Promoting Schools programme involves teachers leading a group of students to look at health-related issues in the school. The goals include creating an effective learning environment, helping students to develop life-long skills, values and health behaviours to support healthy and fulfilling lives, and empowering community members to identify and address health issues.

The You Can Do It programme focuses on getting along, organisation, persistence, resilience, and confidence. These foundations provide a structure for teaching, modelling, and reinforcing the school's expectations, which include being responsible for behaviour, treating the environment and other people with respect, and behaving safely and sensibly.

\section{Community experts at Owairaka School}

Owairaka School has a long history of including community experts in school learning activities. As one of the teachers said, "I haven't known this school not to have community engagement". These community experts include parents, caregivers, and whānau, as well as local business people and members of the wider community without children at the school. Owairaka School also has a steady flow of international volunteers, mostly young people in their "gap" year, who come to work at the school through Travellers World Wide. These visitors stay between a fortnight and two terms, and bring with them a wide range of skills and life experiences which the school staff see as beneficial for their students.

The community volunteers are involved in a wide range of school activities. These activities range from leading cultural groups (at the time of our visit there were eight), leading or supporting school-wide events or programmes, and class-based activities.

\section{Community experts and Garden to Table}

For the purpose of this case study we have chosen to focus on the inclusion of community experts in just one programme-Garden to Table. We hope that through this one example we can illustrate the general principles of community inclusion that operate in all aspects of life at Owairaka School.

5 To join Garden to Table, schools need outdoor spaces for growing food, for storing garden equipment, and for waste management (such as a compost and worm farm). Schools need a kitchen with refrigeration and space for cooking lessons, storing equipment and pantry supplies, and for children and adults to share the prepared meals together. Schools need the support of the principal and the board of trustees, of teaching staff, of whannau, and of the local community. The costs include a set up, development, and training fee of $\$ 2500$ with an annual fee of $\$ 550$ per annum after the first year, along with ongoing staff and supplies costs. 


\section{4. \\ How did it work?}

\section{Structures and processes}

At the time of our visit, children from Year 3 and 4 classes had a Garden to Table session once every 2 weeks for a block of approximately 1 hour and 40 minutes. For each session the class is split in two (with half working in the garden and half working in the kitchen), meaning that each child has one kitchen session and one garden session every 4 weeks. However the intention was to expand the programme to include Year 5 and 6 students the following year.

The school has allocated roles and funded time for recruiting, inducting, and supporting volunteers across all of the programmes they run. One of the associate principals (AP) has a "big picture" role and is responsible for organising volunteers and timetabling.

With Garden to Table, the associate principal liaises with the kitchen specialist-a classroom teacher who co-ordinates and inducts the volunteers as well as running the kitchen for 2 days a week. The more experienced volunteers then work alongside the newer volunteers, providing them with support and "apprentice" style learning.

The inclusion of volunteers is also supported through timetabling. The school has allocated a slot on the timetable for Garden to Table that is maintained in the face of competing priorities.

We might shift other things on the timetable but we never shift Garden to Table. That's a key thing for our kids. (Associate principal)

\section{Enlisting volunteers and making volunteers feel welcome}

One of the reasons Owairaka School has been able to build such a wide and sustainable network of community volunteers is the shared belief that everyone in the community has expertise that the students can benefit from. The school staff consider that it is just a matter of finding that expertise and working out the best way of sharing it.

Every volunteer, whether they're international or not, like every person, brings something pretty special. It's just a matter of utilising that and matching that with students ... Some of them have language skillsit could be anything. It is just a matter of us being smart around that. (Principal) 
To me, there are experts out there and we welcome them in. We'd love to get every single parent in. We're always striving to get more and more in. (Teacher)

Teachers described how they did not just wait for volunteers to come to them but were proactive about finding and including them.

I shoulder tap parents I notice who are passionate about gardening. (Teacher)

If you need something, you just say to someone "This is coming up. Do you know anyone who could help?" You just put out the word and people volunteer. It's just how it is here. (Teacher)

Teachers found that once volunteers were established in the school, they, in turn, worked to include others.

They [volunteers] are good at bringing in other people. They make connections with other people that we might not be able to make. We are open. We say "Come on in. What can you offer us? What can you offer our kids?" And then we'll work out how to make it work. We never say no. They'll say "I was having a chat with so and so" and we'll say "Great, bring them in." There's a sense of: "You're very welcome here" and "Who else might you know?" We continually take those opportunities and make sure we're nurturing them, so that when something does pop up you can say "Oh that sounds exciting ..." [We're up for] any opportunity that rears its head. (AP)

The teachers at Owairaka School also described working hard to create an environment in which volunteers felt comfortable and valued.

With the community and parents, it's making sure you greet then and thank them-make them feel valued and appreciated. (Teacher)

The volunteers also commented on this.

[The] school values us a lot-welcoming smile, a lot know your name and the child's name, enthusiastic, friendly, say hello, know your child. (Volunteer)

School staff saw Garden to Table as an important vehicle for bringing community members into the school in a non-threatening way because gardening, food preparation, and cooking are skills that many people have and feel comfortable sharing.

\section{Promoting community experts' ownership and agency}

Owairaka School has managed to build and sustain the involvement of community experts at their school partly because of the high level of ownership and agency held by the volunteers. Garden to Table volunteers contribute to organisational matters (such as organising replacements when someone is sick), the design of the activities, and problem solving. For example when one of the Garden to Table volunteers noticed that, because of an anomaly in the timetable, two of the senior classes were going to miss out on their pizza oven day, she went ahead and planned some extra sessions and found some other volunteers to help so that no one missed out.

This high level of ownership and agency has the dual benefit of saving teachers' time and increasing volunteer engagement because volunteers have a stake in what goes on. They realise their involvement is not just token and that if they are not there, the children will miss out.

This high level of volunteer ownership and agency did not just happen but came about because the staff actively promoted it through their belief in the value of volunteers, and they trusted in the capacity of volunteers to share their expertise with students. 


\section{5. \\ Curriculum}

We were interested in the relationship between the curriculum and the inclusion of community experts at Owairaka School. We begin this section with a description of staff views of curriculum at Owairaka, and the extent to which these views enabled the involvement of community experts. We then go on to consider the impact that the inclusion of community experts at Owairaka was seen to have on shaping the curriculum.

\section{A curriculum that enables involvement of community experts}

We found that Owairaka School had a curriculum that enabled the inclusion of volunteers. In the first instance it is a curriculum centred on people and place.

\section{A curriculum centred on people and place}

Owairaka School staff viewed curriculum as deeply connected to people-their sense of community and their sense of place.

Our curriculum is centred around people and environment. (Principal)

It's the people for everything-for Enviro Schools, for Health Promoting Schools, for Garden to Table- it's the people who come through. (Principal)

The principal used Garden to Table as an example of the centrality of people in curriculum at Owairaka, arguing that while Garden to Table might appear to be mainly about food, it is ostensibly about peopletheir wellbeing, identity, diversity, belonging, connection, and inclusion.

Often when you think about [Garden to Table] you can think of the healthy food but in fact it's about the people and the health around well being. It's that stuff around culture, around difference, around who we are-because we are a very diverse community, hugely diverse ... So that understanding about the place for people that food brings, uniting us together and sustaining us because it's a commonality. And again it's that link with community because we all need food, we all need lovely water, we all need to feel good in ourselves, we're all aspiring for good things and potential around our kids. (Principal) 


\section{An integrated, spiral, and cumulative curriculum}

Staff described the curriculum as rich, involving themes that build through a child's entire time at the school, rather than as a series of short topics that stop and start. Areas of study are thought about in terms of years rather than weeks or terms. One teacher gave as an example the way in which teachers planned for 2016 to build on the learning that occurred during a study on bees carried out in 2014, altogether encompassing a 3-year period of time.

Last year for science we did a big study about bees for example. So the bees are in the kids' minds and so next year we're going to weave the environmental side into it, and Garden to Table. So it's not just something your class thinks about in term 4. They're learning about it weekly, termly, they're always building on it. (Teacher)

The curriculum at Owairaka is integrated with teachers' thinking, planning, and teaching less in terms of separate subjects or programmes and more in terms of big ideas.

Everything knits together. It is difficult to describe our curriculum because we look at it holistically. We don't just see it as narrow areas like English, science, maths because everything is involved. (Principal)

The reason I think Garden to Table works so well is that it's just part of the norm. It's not like "Let's stop what we're doing and go to Garden to Table". It all links together. The kids have been planting and learning about plants since day dot. They've learnt to care about the environment and that links to Garden to Table. (Teacher)

\section{A curriculum responsive to community}

The curriculum is informed by, and responds to, what is happening in the local community and environment. Curriculum was seen as a tool through which the community and the local environment can be sustained and can grow. The Year 3-4 teacher, for example, had the role of making connections between the science curriculum and the community.

Part of my job is to make a link between science and what is happening in our school and community. (Teacher)

Staff considered that the integrated, holistic, spiral, fluid, and responsive nature of the curriculum made it easy for them to find a space for all volunteers regardless of their areas of knowledge and skills. Because everything is seen as connecting, and because curriculum is personalised, any kind of contribution can be woven into the curriculum at almost any time.

\section{Impact of community experts on curriculum}

Staff described the ways in which community experts at Owairaka School contributed to shaping, planning, and delivering the curriculum. The school gardens represent a range of the cultures in the community. The plants that are grown, and the ways they are harvested, prepared, and cooked are informed by the cultural make up of the community.

We don't have meat in the kitchen. We're very conscious that our food meets different criteria around our cultural mix. (Principal)

Apart from our working gardens there are cultural gardens-African gardens, Asian gardens, zen gardens. Hopefully all our children can find a space in our school they can connect with in some way. (Principal)

The knowledge and skills of the particular volunteers are passed on to the children as they work together. The principal gave as an example the story of one of the volunteers: 
[Volunteer] loves food and she brings that Pakistani, Muslim-based understanding. So a lot of recipes she will contribute to. We choose recipes from places that our children have connections with and [Volunteer] can make cultural connections to the food. She is vegetarian and Garden to Table is vegetarian so there is a good match there. She has a lot of understanding about vegetables and how they can be used.

The school staff saw the cultural, linguistic, and ethnic diversity of their community as a particular strength for Garden to Table because the community holds a wide range of knowledge about different ways of planting, tending, harvesting, preparing, cooking, and serving food.

The teachers also considered that their work with community experts contributed to the purposeful authentic, hands on and embodied nature of curriculum at Owairaka School.

It's so much more hands on and authentic. There's a richness it brings to curriculum and it's just engaging and motivating for so many of our kids. It brings a different and real front for bringing through the principles of the curriculum and the key competencies. (Principal) 


\section{6. \\ Effect on teachers and teaching}

Involving community experts in school not only influences the "what" of teaching but also the "how". One of the questions we are interested in is the effect the inclusion of community experts might have on teachers and their teaching.

Several teachers talked about the process of adapting to a school with large numbers of community experts involved in a wide range of learning activities.

This is a school that is really open. When I first arrived I was a bit shocked. I came from an intermediate school where there are not a lot of other adults around. You just saw students and teachers. When I arrived [at Owairaka School] there seemed to be people everywhere all of the time and I was trying to figure out who these people were. (Teacher)

They described how teachers at Owairaka School needed to arrive with or be able to develop the qualities needed to work with members of the community. These qualities included being open, flexible, tolerant, and willing to take risks and to try new things.

When we interview people for our school these are the qualities they must have-they must be happy to work alongside a parent, a community member, a teacher aide, an RTLB, and support staff. You have to be happy to have all of these people in your classroom because we believe it takes a village to raise a child. If you're a bit of an island then we are not the right school for you. (Teacher)

You can't be one of those teachers who close their door. We have an open door policy. Parents can pop in at any time and see quality teaching-and they do. You need to be organised. You need to be flexible. You need to be open and friendly and welcoming to all. (Teacher)

You need to be willing to give things a go and try things out of your comfort zone. So if you're not very comfortable gardening, you still have to get in there and give it a go. You need to be okay with risk taking. (Teacher) 
You need to be the type of person to know you are not an expert at everything and be willing to try new things. I'm leading the Samoan cultural group this year. I don't have much of the language and I don't have a lot of rhythm but I'm giving it a go-l'm there to support. I'm there to help out. I'll give it a go and that's our attitude here. I don't know how to do it but I'll help. (Teacher)

Teachers also considered that working with community experts foregrounded the enacted nature of curriculum and learning because at Owairaka School curriculum is something that you do. It is embodied, involving the whole body, not just something that happens in your head.

To get a job here you need to believe that students learn just as much in Garden to Table as sitting in a classroom with a book. (Teacher).

\section{Opportunities to be a learner and to connect with the community}

Including community members at Owairaka school provided teachers with the opportunity to take on different roles in relation to students and parents, and to feel more connected with the wider community. The kitchen specialist described how she worked with teachers in Garden to Table.

Teachers often have a group. I work with them as a colleague-treat them as a volunteer assigned a job. [One teacher said] "You always make me do the hard things" and I said "You are learning too". (Kitchen specialist)

The students we spoke with also observed that their teachers took on a different role when working alongside community experts during Garden to Table.

Teachers are different in the kitchen and garden as they're quiet and let you do things-the garden teacher is not really a teacher but you listen to her. The classroom teacher is not the kitchen expert-our teacher doesn't know how to cook so we share our knowledge. The teacher learns like us. (Student).

Teachers enjoyed the opportunity to take on a different role and found that it enabled them to connect with others in the community in ways that had not been so easy to do when in the more traditional teacher role.

It's nice to work alongside people in the community in a different role, because when you're the teacher there is that respect and that little bit of distance, whereas with Garden to Table that boundary or distance disappears a little bit. I come to know how they really feel about school and about what they see here. I actually get to know these parents, these community members in a different way ... And just to know parents on a different level just feels really nice. (Teacher)

It feels like you're connected to the community more. (AP)

Teachers also commented on the things they learnt from community members.

I pick up little tips about gardening. (Teacher) 


\section{7. \\ Effect on students and their learning}

We asked the school staff and volunteers to describe the effect they considered the inclusion of community experts at Owairaka School had on the students.

\section{A sense of belonging}

Staff considered that including community experts in school provided students with a sense of belonging. They saw this as particularly important in a community with many migrants from different parts of the world, including a large refugee population.

It brings belonging. We know how important belonging is for our people, for our kids. That belonging-it might just be as basic as "I know you" or it might just be waving. (Principal)

The principal described how the presence of community experts in the school was reassuring, especially for some students.

That [seeing adults at school from their own culture or who they know] reassures our kids to be that much more engaged in what they are doing. I don't know how to explain it exactly. A kid might even be working away from that adult that they know but it makes them feel that much more reassured, comfortable, and attuned because they know that there are people around who can support them if they need it. (Principal)

The students we spoke with also talked about the feeling of reassurance that came with having community experts in Garden to Table.

It's different as you are in a big room where people have experience-it's good to have more people who know what they're doing-someone there to make sure nothing goes wrong. This is better than the inclass way ... You don't get as nervous. (Student)

Volunteers act like you are doing it by yourself but they are there to help-they take the heat. It's good. (Student) 
The inclusion of community experts provided students with opportunities to see their own cultures represented at school and to hear their own languages being spoken and their cultural knowledges, skills, and expertise being used and valued.

The inclusion of community experts also helped students feel more connected to the wider school community in which they lived.

The relationships with those community workers-it provides an opportunity for follow up, for connection. Connection is really important for our kids. (Principal)

\section{Purpose, agency, authenticity}

As well as providing students with a sense of belonging at school, the adults we interviewed considered that including community experts at school helped students to see their learning activities as authentic and purposeful.

It's not a contrived situation because when you are relating to different groups of people you are looking at the listening and how the kids can contribute. There's such a blend in a real world situation for our kids. (Principal)

Including community experts at school helped students develop a sense of agency and be able to participate and contribute as part of that wider community.

Children feel part of something bigger when interacting with volunteers. That they do have a voice outside their classroom and experience of different people in different age groups. A different world view of what they can be part of. (Kitchen specialist)

This agency gave students the confidence to go out and find experts as they needed them. One teacher described, for example, how the students organised an expert for building the pizza oven.

The children wanted to build a pizza oven and they found a man to help them do it-that was his job. The students worked out what we had to do to make a pizza oven and then we realised we could only get so far without an expert. So they googled "pizza oven expert" and found him. He came and talked with the students about different designs for the oven. We fire it up every term to make pizza. It becomes normalised that you would find an expert. (Teacher and kitchen specialist)

\section{Opportunities to work with diverse others}

Another benefit staff saw in working alongside community experts at Owairaka School was the opportunities for students to work with diverse others and diverse ideas.

One really powerful thing is relationships with other people-with older people or with people from different backgrounds. (Teacher)

One of the volunteers described the school as being "exceptionally lucky" at having such diversity in the community to draw on.

In the context of Garden to Table the diversity of ideas, knowledge, and language related to planting, tending, harvesting, preparing, cooking, and eating food.

We have a world map in the kitchen and a lot of the menus come from different places in the world. It's so special if there's a child from the country-Sri Lanka, Russia-our children can learn directly from each other and from the food. (Kitchen specialist)

Like we've had people who've taught us how to get coconut milk ... We've had parents come in and teach us how to do a recipe from another country, and things like that. Just the wealth of knowledge that is out there, that is usually hidden. (Teacher)

Staff considered opportunities to work with people of different ages, from different cultures, and with different languages, knowledges, and experiences helped students take a curious and open stance 
towards difference amongst their own peers at school, including the different types of food children brought for lunch each day.

It breaks down the barriers when they're sitting next to someone from another culture at lunch time. It takes away the strangeness of what they might be eating-sushi or Somalian bread-that might look a bit different, because we eat all different kinds of food in Garden to Table. It breaks down those barriers and gives them an appreciation of the different foods that are out there. (Teacher)

It also helped them to understand that people can communicate in different ways.

What do children get-a different way of understanding that people will communicate with them in different ways. (Kitchen specialist)

\section{Opportunities to learn from adults other than teachers}

Teachers observed that community experts brought with them not just different knowledge and skill sets, but also different ways of relating.

There is a difference in the way they [community experts] relate to kids. There is a knowing and an understanding. We think that it supports achievement especially for some kids. (Principal)

They have different ways of communicating, there's more of a relaxed banter because they are not an authority figure but still respect you and learning happens-respect, turn-taking, general life skills. (Volunteer)

Volunteers talk to them differently-talk to the children as people and not just lecturing them. (Kitchen specialist)

The kitchen specialist was in the unique position of being seen by students in two different roles: as a community volunteer during the 2 days she worked in the kitchen; and as a teacher for the 3 days she worked in her classroom. She observed that she and the students related differently when she was in these two different roles.

As a classroom teacher you build up your class as you want to run it-you know your rules and there's that magical teacher thing. I'm seen here [in the kitchen] in a different role. It is very different. The children see me as a volunteer-a member of the wider community. You get kids wanting to come in at lunchtime and hanging out. It's nice meeting lots of children ... Children feel part of something bigger when interacting with volunteers. That they do have a voice outside their classroom. [They learn from] different people in different age groups. A different world view of what they can be part of. (Kitchen specialist)

The students we talked with enjoyed working with the volunteers and also observed that volunteers worked with them in different ways from teachers.

I like the opportunity to work with people you don't usually work with. (Student)

Some thought the volunteers were different from the classroom teacher and some thought they were similar but saw that the adults were there "to help as well" and were "really nice". They noted that their regular teacher behaved differently in Garden to Table-usually because they were not an "expert".

\section{Knowledge and skills}

We identified several ways in which Garden to Table enhanced knowledge: learning about ecological sustainability; learning about gardening and cooking, and healthy and adventurous eating; and learning about other subjects, especially mathematics, through gardening and cooking.

The students were clearly able to articulate what they learnt through their involvement in Garden to Table, Enviroschools and Green Days. 
We are an Enviroschool. [We have Garden to Table] to learn how to cook and garden. Being a green school you can't just let plants sit and rot. It's to help us learn about food and plants, cook and use our plants, expand your knowledge with cooking-the pans, and in the garden how to plant and weed. (Student)

To learn things so that when we have green day we don't cut things or destroy things. (Student)

There was a strong emphasis on learning about other cultures' food and "where it comes from": "It's good to have meals from around the world-American meal, Italian meal."

The garden specialist acknowledged that they needed "to teach the students basic ideas-not throwing food, not walking through the garden, table manners". Slightly more students preferred cooking to gardening and all appreciated that they shared a meal at the end of the session.

The kitchen specialist explained:

It's wonderful to see children eating healthy food, trying new food that they've never tried before and from different cultures... They are learning directly from each other and from the food. I love seeing the progression of the kids from when they first start-at first just sitting looking and then gradually trying things. With some it's instant, with others it takes a long time.

The students told us they had learned many new things: new recipes, how to use gardening and cooking equipment, how to cut properly and straight, how to use the pizza oven, making and eating things they had not heard of (for example, putting beetroot in the salad), new plants, and how effective herbs such as coriander are in flavouring food. They were proud and somewhat surprised to learn that they and other students were good at particular tasks. They told us these included cutting trees straight with a hacksaw, planting seeds, knowing all about plants and herbs, using the sprayer to kill bugs, picking food and flowers, and cutting and mincing.

Some kids brag about it to their parents-do you know what this plant is? So they can teach their parents. (Student)

They also learned from mistakes or less enjoyable tasks such as cutting onions, getting dirty when gardening, using the grater and cutting oneself, or having to wait for the gardening teacher to give them a new job.

The garden specialist described how the students learn different ways of planting, caring for, gathering, and using different vegetables from different cultural groups. They make compost, lash together bamboo to make tepees for beans, they drill holes in rubbish bins to plant potatoes, and they prune, saw wood, and tidy up the trees. They learn about honey and caring for chickens and how to make and use compost. They learn about the seasons and tasks that are seasonally dependent.

The kitchen specialist valued Garden to Table for the "social aspect which is huge".

\section{Opportunities for all students to experience success}

The types of activities and conversations in which the community experts engaged students (including those students with high behavioural needs and special education needs) provided opportunities for some students to demonstrate and build skills and knowledge that would not have otherwise been possible. Teachers and volunteers commented in particular on hands-on activities.

Students love it. They are enthusiastic and fun to be around ... It's a hands-on thing. (Teacher)

The students we spoke with also referred to the concrete and hands on nature of Garden to Table.

It's nice for gathering things, cooking as a team, using everything-honey, plants, eggs, things around you. (Student)

Taking a little bit of the environment and using it as knowledge and learning about it as you are cooking or gardening-what plants are and what trees are. (Student) 
You get to eat after you make the food. It's really good that you get to eat stuff. You get to make things without having to buy anything. We all get an opportunity to have different experiences to make different types of food. (Student)

Garden to Table gave students the opportunity to work with adults who had different skills and knowledge from their teachers and not always focused on in traditional school classroom learning.

Kids can look to grow their skills and qualities in a different way. It allows them, we believe to experience success. It's an avenue where all of our kids will experience success. (Principal)

It is multiple eyes on our kids' learning, and the opportunity [for our kids] to learn in different ways. (Principal)

It's really good for kids who aren't as able at reading and maths, but might be really strong. So when they do the digging, or the sawing, or the cutting-things they might be really good at-the other kids see that even if they might not be strong at maths or reading, they've got skills in other ways, or they've got leadership outside of the classroom. (Teacher)

I have SENCO [Special Education Needs Co-ordinator] responsibilities and it [Garden to Table] is a programme that the children adore-every single one of them. We find children with high behaviour needs just thrive in Garden to Table. (Associate principal)

The students we talked with confirmed that when working with community experts as part of Garden to Table, some students demonstrated skills and knowledge that they had not previously had the opportunity to demonstrate in the classroom.

You get to see people's skills that you haven't seen before. (Student)

There's a tiny girl in the class who doesn't really speak and she's shy but in the kitchen she was on task and actually doing it. She usually lets everyone else do it ... Another boy showed us he knew all about plants and herbs which we didn't know. (Student)

Students behave differently in Garden to Table-in class doing maths or writing usually you have to do it individually, but in the kitchen people stay on task. Other people are quiet in class but in the garden or kitchen they take the lead. (Student)

The garden specialist described how volunteers are able to talk to children as people, "not just lecturing to them" and stressed that these interactions are different from ones that students have with classroom teachers. Several volunteers made similar observations:

It is a different way of understanding that people will communicate with them in different ways; different ways of communicating; it's relaxed banter. I am not an authority figure but they still respect you and learning happens-respect, turn-taking, general life skills, a chance to cook. (Volunteer)

The principal observed the positive effect these experiences of success had on students' confidence.

There's such a blend in a real world situation for our kids. Some of our kids-the confidence they grow in that time is wonderful. They are different kids than they might be in, say, maths time. (Principal)

And we saw evidence of this confidence in the students we interviewed.

I'm good at cutting trees straight with a hacksaw. I'm strong and [name] was doing it naturally. (Student)

One teacher spoke at length about the positive impact she considered working with community experts as part of Garden to Table had on her students' oral and written language.

Our curriculum is successful for our kids. Compared with other schools like ours, our stats stack up pretty good. We do pretty well. Something here works for our kids. (Principal) 


\section{8. \\ What was the impact for community experts?}

\section{A sense of belonging}

The school staff we talked to saw a number of benefits for the community experts involved and the community as a whole-the main one being a sense of belonging to the school and the community.

There's that human connection but also that sense of belonging I think. (Associate principal)

Just to have them (community experts) see that school is not a place to tip toe around, school is actually part of them as well, and I think that's nice. (Teacher)

For example, there's a mum at the moment with young children at home and I could see she was feeling kind of isolated, but maybe school is not her thing so I suggested she volunteer in Garden to Table. Now I see her chatting with the kids with a big beaming smile and I know she is going away feeling good about herself, and it all flows on. (Associate principal)

The school staff also considered that another positive effect for the volunteers was the satisfaction of sharing their skills and knowledge.

There's something [some satisfaction] about imparting skills. A lot of our volunteers have lots of skills they can teach. They can see the children are learning so much [from them]. (Associate principal)

[What do the volunteers get out of it?] They see the value of it for the children, the conversations that they have and the joy that they bring [to the children]. They hear the children go “Oooh, it's Garden to Table". (Associate principal)

The kitchen specialist also observed that volunteers value their interactions with the students and the ability to sustain a relationship with them. She considers that the enjoyment is reciprocal.

It's lovely that some of the kids get to know [garden volunteer] who will pop back to talk to them. She found the school through Volunteer Auckland and is motivated by the joy of seeing what children can do. You have really nice little conversations because you're working in a little group. Seeing those 
developments and establishing those relationships and feeling like you're part of a bigger thing. It works both ways-for children and volunteers to feel as if they're part of a bigger thing. (Kitchen specialist)

Staff members agreed that the volunteers gained from their relationships with students.

They feel they want to connect with people. They enjoy our children. Our kids are very welcoming. They treat all adults the same, whether you're a teacher, a teacher aide, a volunteer. (Associate principal)

The specialists and the volunteers identified many benefits in being part of Garden to Table. They included: meeting other parents and other members of the community and getting to know the teachers better; working with children other than their own; and learning new recipes and different cultural approaches. They commented that they were exceptionally lucky as there was such a diverse range of people involved.

It's not only parents but other members of community-it's fun and enjoyable, someone to chat to and to help in the community. To understand what people in the community do. Grandparents and others come as they enjoy it. (Volunteer)

The benefits are the hugs, their faces lighting up, the little questions. (Volunteer)

\section{Opportunities to learn new skills}

The garden specialist talked about the opportunities she had to develop skills directing and relating to students by observing the teachers carefully and following what they did.

I have my favourite three to four teachers. I observe them and ask them what to do. The senior leadership team are very supportive. (Garden specialist)

She was finding her second year as the garden specialist easier.

I'm more experienced this year. I make sure there are enough tasks to keep everyone busy for an hour. I try to encourage independence and expect that older kids will remember things and not need reminding. (Garden specialist)

\section{Understanding and influencing the curriculum}

Teachers considered another benefit for volunteers was that they could develop a deeper understanding of the curriculum through being involved in its delivery. The volunteers we spoke with were enthusiastic about volunteering, having been attracted to it to find out more about what their children were doing and learning so that they could help them. They wanted to be involved in supporting the school. They were also appreciative of the school's approach to their children and felt safe to offer alternative approaches.

This was also beneficial for the school because it meant that programmes like Garden to Table had parental support.

They are quite happy for their kids to be involved in the programme. At a different type of school they might see time out of the class and not doing reading and maths as not a good thing. So that's part of it too-that our parents think it is well worth doing. So we don't get any resistance that way ... Because that attitude is there it's easy to drum up the enthusiasm, the businesses, the money to make it work. At another school it might not. (Teacher)

The volunteers we spoke with were attracted to Garden to Table as it was not a "real" classroom and because of its mission. They applauded the fact that it was teaching "life skills, the life cycle, using our resources, understanding using everything that can be used-what to do with things left over-food and rubbish". 


\section{9. \\ What was the effect on the wider community?}

We asked the interviewees if they thought Garden to Table was having an effect on the wider community. They considered gardening to be a connecting activity for different cultural groups.

One volunteer thought that the school could "have teaching days for the community to learn new processes from the kids".

Teachers thought there were several benefits for the community.

[What is the effect on the community?] We sell stuff like worm tea at the office which is one little way of trying to spread the message through the community. With the healthy eating children will go home and talk about what they've been eating and that will sometimes filter through. We have working bees. We don't have communal gardens on the school site-that is something we might work towards in the future-but if you want to help yourself [to produce] in the summer holidays you can. We use up everything we grow in the term time. We often use produce for Make and Take lunches-in the winter time we make soup. (Teacher)

There are opportunities to connect with businesses with a similar philosophy. For the last two years [a local business] has offered goods for our auction [a fundraiser]. I had a chat with one of their business woman. She said "I'm fascinated with what you are doing" and wanted to hear all about it. I suggested she come and take a look one day and so she came and visited. She loved it and that she could be part of it. She was bubbling. She was so excited that she could tell her friends back in America that in New Zealand you can be part of the local school. It was so lovely for the other volunteers working on that day she came in because she was able to share with them what she was doing. So it was connecting across the community. (AP) 


\section{0. \\ Challenges and considerations}

\section{Fundraising}

The teachers and specialists considered fundraising and concern about funding as a major challenge. The Garden to Table Trust provides area co-ordinator support but the school must find a set up, development, and training fee of $\$ 2500$ and an annual fee of $\$ 550$ after the first year, ongoing specialist staff costs, and resources and supplies for the garden and kitchen. Financial considerations limit the number of students who can take part each year and the number of sessions each student can take part in. The school fundraises and budgets for the specialists' salaries and for some kitchen supplies but there is "nothing for seedlings".

Challenges are a lack of volunteers and money but we are so lucky having a great group of parentsfriends of the school-who do fundraising. Gradually Garden to Table are getting more sponsors. (Kitchen specialist)

Funding is a challenge. When we first started it took a lot of work but we've been really lucky that we've always had a strong garden teacher and a strong cook, and that we've been able to fund them. In a perfect world we'd have enough funding to be able to offer it to every child every two to three weeks every year. (Teacher)

Funding depends on the Board of Trustees and the principal being able to find money. It worries me that such a great programme could be cut. (Kitchen specialist)

The school fund-raises through yearly auctions, "make and take" days once a term, sausage sizzles, family nights, quiz nights, and by selling produce-for example, eggs, honey and worm tea. Garden to Table also gets funding from a school fundraising group.

We fundraise-it's something we prioritise. Next Tuesday we are running a muffin day to raise money for tools. (AP) 
We have an auction every two years to pay for it. We make sure that we put space aside for future gardens. We've built stuff to last, like putting in the pizza oven to make Garden to Table an exciting thing. (Teacher)

\section{Community experts are not teachers}

One of the challenges is when the volunteers' ways of doing things does not align with the schools' way.

In the kitchen especially, it's important the volunteers don't do the work for the children. Whereas for [volunteer], from her culture the children don't do it, the children watch. So we have had to have quite a few conversations about how important it is that you are assisting, you're facilitating, you're guiding. You're not actually doing it for them. The children are the ones who have to do it. You might show but then they need to do. It is when you are doing the cutting or the slicing or the blending that the connection happens between the language and the task. (AP)

You do have to chat with people so that they know the expectations. They need to understand how our kids need to behave and if it falls down, what they can do about that. And likewise they need to know how we talk to our students. We're very careful about the way we speak with students. Our approach is strength-based. We focus on what's positive and what's known to take kids on in their learning. So they're structures if you like. (Principal)

Safety of children when they are working in small groups with volunteers was not discussed as an issue but the school is very aware of its obligations and mentioned, for example, the Vulnerable Children Act.

We do police checks on the people who are working here in a sustained way. It keeps everyone safe. (Principal)

\section{Accountability}

The principal observed that one of the challenges faced by the school in promoting a fluid, responsive curriculum was that it was difficult to describe and record in ways needed to meet external accountability requirements such as ERO. 


\section{1. \\ Sustainability}

Owairaka School was drawn to Garden to Table partly because of its involvement in Enviroschools-the school had a long history of educating children, and by extension their families, about environmental sustainability.

It has been possible to sustain the involvement of community members in Garden to Table because the inclusion of community at Owairaka is bigger than just one programme. The structures, systems, and culture of the school are set up to support the involvement of community members. The inclusion of community volunteers is supported by school leaders and is embedded in the culture of the school. This supportive culture comes from the principal and the senior leadership team who embrace the principles of community involvement and the environmental sustainability learning and teaching that Garden to Table embodies. While funding issues could jeopardise the growth of the programme, it is likely that Garden to Table will continue to be prioritised because of the commitment of students, staff, volunteers and the community.

[We sustain it because of] what it brings for our community and kids. It is completely, utterly believed in and valued. It is something that we think our kids need. They grow from it ... We are student centred and we can't do that without our community. (Principal)

It's not one person's baby. It's the school. It's embedded within the culture of the school.

(Associate principal)

The principal is on board. It's not like a class teacher is trying to lead it and the principal is so so. It's actually led from the top. If the whole staff is not on board it's hard to sustain it. We highly believe in it. We have an auction every two years to pay for it. We make sure that we put space aside for future gardens. We've built stuff to last, like putting in the pizza oven to make Garden to Table an exciting thing. I think that's a big thing-that management believe in it and want it to succeed so they support it. And then having the enviro-team and the science team behind it as well. So it's a big voice instead of just one or two people. (Teacher) 


\section{2. Discussion}

We chose Owairaka School as a case study site because we knew that it had a strong Garden to Table programme that involved a range of volunteers as gardeners and kitchen helpers. The students, staff and volunteers talked enthusiastically and wisely about their involvement in Garden to Table.

Until we visited the school to interview students, staff, and volunteers involved in Garden to Table, however, we had not appreciated the extent to which wider school values, policies, and processes of community engagement underpin the school's approach to learning. The values are clearly articulated by every member of the school community. That the school embraces its diverse community is apparent in the physical environment (signage, gardens, artwork, buildings) as well as in the large number of volunteers who are involved in the school in a variety of projects, including Garden to Table. Clearly, Garden to Table is not seen by anyone as an "add-on" but is fully integrated into the curriculum for Year 3-4 students (and in 2016, for students in Years 5-6). Community volunteers are seen by the school to bring rich and diverse knowledge and skills that benefit students and teachers. The students appreciated the differences and similarities in working with adults who were their teachers and who were volunteers. The students are immersed in ways of learning and being that can and should shape the way they interact with their worlds in the future.

Garden to Table exemplifies the tenets of the sixth future-focused principle from Bolstad et al. (2012) that schools, on their own, can no longer be expected to provide all of the knowledge and expertise that today's learners need. Students therefore need opportunities to better access knowledge and expertise within the community. Students also need opportunities to develop their capabilities in authentic contexts (for example, using knowledge in ways that contribute to the community, as well as to their own learning and development).

There is also reciprocal learning for the adults involved in the many projects the school has that involve community members. The school acknowledged that being a volunteer helps parents and other community members to better understand the curriculum and their children's learning. Teachers learned new skills from volunteers that could be adapted in classrooms. Volunteers learned teaching and management skills from teachers that they could use in their volunteering role and in the home and community. There were significant social benefits for volunteers to be seen to be part of the school community. 


\section{References}

Bolstad, R. \& Gilbert, J., with McDowall, S., Bull, A., Boyd, S., \& Hipkins, R. (2012). Supporting future-oriented learning and teaching-A New Zealand perspective. Wellington: Ministry of Education.

Flyvbjerg, B. (2006). Five misunderstandings about case study research. Qualitative Inquiry, 12, 219-245.

Ministry of Education. (2007). The New Zealand curriculum. Wellington: Learning Media.

Yin, R. (2003). Case study research: Design and methods (5th ed.). Thousand Oaks, CA: Sage Publications Inc. 


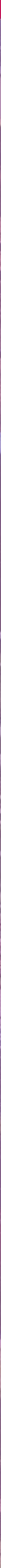

